\title{
INTERRELATIONSHIPS BETWEEN HYPERURICEMIA, METABOLIC SYNDROME AND CHRONIC KIDNEY DISEASE IN PATIENTS WITH DIABETES MELLITUS
}

\author{
Adriana BAIDOG ${ }^{1}$, Simona BUNGAU ${ }^{\circledR}$, Tapan BEHL ${ }^{3}$, loana RATIU ${ }^{4}$, Raluca A. CORB ARON ${ }^{5}$, \\ Francesca URSU ${ }^{2}$, Liviu LAZAR ${ }^{6}$, Cosmin M. VESA ${ }^{1,5}$
}

${ }^{1}$ Clinical County Emergency Hospital of Oradea, Oradea, Romania

${ }^{2}$ Department of Pharmacy, Faculty of Medicine and Pharmacy, University of Oradea, Oradea, Romania

${ }^{3}$ Chitkara College of Pharmacy, Chitkara University, India

${ }^{4}$ Department of Medical Disciplines, Faculty of Medicine and Pharmacy, University of Oradea, Oradea, Romania

${ }^{5}$ Department of Preclinical Disciplines, Faculty of Medicine and Pharmacy, University of Oradea, Oradea, Romania

${ }^{6}$ Department of Psycho-neurosciences and Recovery, Faculty of Medicine and Pharmacy, University of Oradea, Oradea, Romania

Received 04 Aug 2020, Accepted 20 Aug 2020 https://doi.org/10.31688/ABMU.2020.55.3.11

\section{Abstract}

Introduction. Hyperuricemia is a strong predictor of an altered metabolic status. There are complex interrelationships between hyperuricemia, type 2 diabetes mellitus (T2DM), metabolic syndrome (MS) and chronic kidney disease (CKD).

The objective of the study was to investigate the impact of hyperuricemia on the prevalence of MS and glomerular function in patients with T2DM.

Materials and methods. This retrospective study included 300 patients with T2DM, hospitalized for one day in the diabetes clinic, between 01.01.2016-31.12.2018; all the data used for the analysis were obtained from the medical records.

Results. The prevalence of hyperuricemia was $46 \%$. MS was identified in $88.41 \%$ patients with

\section{Résumé}

Interrélation entre l'hyperuricémie, le syndrome métabolique et la maladie rénale chronique chez les patients avec diabète sucré de type 2

Introduction. L'hyperuricémie est un puissant prédicteur d'un état métabolique altéré. Il existe des interrelations complexes entre l'hyperuricémie, le diabète sucré de type 2, le syndrome métabolique et l'insuffisance rénale chronique.

L'objectif de l'étude était d'étudier l'impact de l'hyperuricémie sur la prévalence de la SEP et de la fonction glomérulaire chez les patients atteints de diabète sucré de type 2 .

Matériaux et méthodes. Cette étude rétrospective a inclus 300 patients atteints de diabète sucré de type 
hyperuricemia compared to $61.73 \%$ in patients with normo-uricemia $(\mathrm{p}<0.01)$; also, all the components of MS were better represented among hyperuricemia patients. The prevalence of CKD (defined as glomerular filtration rate $<60 \mathrm{~mL} / \mathrm{min} / 1.73 \mathrm{~m}^{2}$ ) was $49.28 \%$ in patients with hyperuricemia, while in patients with normo-uricemia it was $25.31 \%(\mathrm{p}<0.01)$. Other metabolic conditions were statistically significantly represented for hyperuricemia patients: obesity ( $88.4 \%$ vs. $61.72 \%$, p < 0.01$)$, hepatic steatosis ( $81.11 \%$ vs. $57.41 \%$ ). The impact of the aggregation of metabolic risk factors in hyperuricemia patients was visible in this study, the prevalence of ischemic heart disease being $83.33 \%$ in patients with hyperuricemia and $72.4 \%$ in patients with normo-uricemia $(\mathrm{p}=0.02)$.

Conclusions. Hyperuricemia is associated with increased MS prevalence and increased prevalence of CKD in T2DM patients.

Keywords: hyperuricemia, metabolic syndrome, type 2 diabetes mellitus, chronic kidney disease.

\author{
Abbreviations list \\ BMI - body mass index \\ CKD - chronic kidney disease \\ CVD - cardiovascular disease \\ GFR - glomerular filtration rate \\ HDL - high-density lipoprotein \\ LDL - low- density lipoprotein \\ MS - metabolic syndrome \\ NAFLD - non-alcoholic fatty liver disease \\ $\mathrm{NO}$ - nitric oxide \\ ROS - reactive oxygen species \\ TGL - triglycerides \\ T2DM - type 2 diabetes mellitus
}

\section{INTRODUCTION}

The contemporary society is confronting with an impressive number of patients who have metabolic syndrome (MS), chronic kidney disease (CKD) or type 2 diabetes mellitus (T2DM); these conditions can coexist, leading to a relevant decline in the quality of life, as well as the lifespan. There is a real concern in conducting research to discover the possible relationships between these disorders and, by means of sanitary management methods, and to implement measures to decrease their prevalence.

MS represents an association of metabolic factors, being an increasingly common syndrome, due to the major impact it has on the health of the population. The characteristics/criteria for the diagnosis of MS were several times defined by the competent authorities in the field until 2009, when a consensus
2, hospitalisés pendant une journée à la clinique de diabète, entre le 01.01.2016 et le 31.12.2018; toutes les données utilisées pour l'analyse ont été obtenues à partir des dossiers médicaux.

Résultats. La prévalence de l'hyperuricémie était de $46 \%$. Le syndrome métabolique a été identifiée chez $88,41 \%$ des patients présentant une hyperuricémie contre $61,73 \%$ chez les patients présentant une normo-uricémie ( $\mathrm{p}<0,01)$; De plus, toutes les composantes du syndrome métabolique étaient mieux représentées chez les patients avec hyperuricémie. La prévalence de l'insuffisance rénale chronique (définie comme un taux de filtration glomérulaire $<60 \mathrm{ml} / \mathrm{min} / 1,73 \mathrm{~m}^{2}$ ) était de 49,28\% chez les patients présentant une hyperuricémie, tandis que chez les patients atteints de normo-uricémie, elle était de 25,31\% ( $<<0,01)$. D'autres pathologies métaboliques étaient statistiquement représentées de manière significative chez les patients hyperuricémiques: obésité $(88,4 \%$ vs $61,72 \%$, p <0,01), stéatose hépatique $(81,11 \%$ vs $57,41 \%)$. L'impact de l'agrégation des facteurs de risque métaboliques chez les patients hyperuricémiques était visible dans cette étude, la prévalence de la cardiopathie ischémique étant de 83,33\% chez les patients avec hyperuricémie et de $72,4 \%$ chez les patients atteints de normo-uricémie $(\mathrm{p}=0,02)$.

Conclusions. L'hyperuricémie est associée à une augmentation de la prévalence du syndrome métabolique et à une augmentation de la prévalence de l'insuffisance rénale chronique chez les patients atteints de diabète sucré de type 2 .

Mots-clés: hyperuricémie, syndrome métabolique, diabète sucré de type 2 , maladie rénale chronique.

was reached, and a definition currently used was issued. Thus, international associations (International Diabetes Federation, National Heart, Lung, Blood Institute, American Heart Association, World Heart Federation, International Atherosclerosis Society, International Association for the Study of Obesity) gathered and, after analyses and discussions, established a consensual description regarding the medical term of MS, so that it is defined by the presence of at least three of the following anomalies ${ }^{1}$ : abdominal obesity, waist circumference $>80 \mathrm{~cm}$ in women and $>94 \mathrm{~cm}$ in men; hypertriglyceridemia $(\geq 150 \mathrm{mg} / \mathrm{dL})$ or the use of lipid-lowering drugs; low serum lipoprotein levels: low HDL-cholesterol $(<40 \mathrm{mg} / \mathrm{dL}$ in men and $<50 \mathrm{mg} / \mathrm{dL}$ in women); high blood pressure: systolic blood pressure $\geq 130 \mathrm{mmHg}$, diastolic blood pressure $\geq 85 \mathrm{mmHg}$ or use of antihypertensive 
medication; fasting blood glucose $\geq 100 \mathrm{mg} / \mathrm{dL}$ or antidiabetic treatment.

The importance of MS is given especially by its consequences, a patient with this disease having an increased risk of cardiovascular disease (CVD) ${ }^{2,3}$ approximately twice as high compared to those without MS, an increased risk of T2DM ${ }^{4}$ and it is also associated with polycystic ovary syndrome ${ }^{5}$, non-alcoholic fatty liver disease (NAFLD), different forms of cancer, and also sleep apnea syndrome. It strongly influences the quality of life, increases morbidity and mortality of any cause, also having a negative economic impact on the healthcare systems. In western countries, the estimated prevalence of MS is about $20 \%$ in the adult population, increasing with age. However, the prevalence of MS also varies according to the population studied, definition used, age, gender, race and ethnicity ${ }^{6}$.

CKD is another widespread disease with a huge economic impact on health systems; it is estimated that around 200 million people suffer from CKD, its prevalence being estimated to $11-13 \%^{7}$ and increasing especially in the elderly population (30\% of people >65-year-old have stable CKD). It is defined by the presence of abnormalities in renal structure and function, with a duration of more than 3 months, evidenced by the urinary albumin/creatinine ratio above $30 \mathrm{mg} / \mathrm{g}$ and/or the decrease of the glomerular filtration rate (GFR) below $60 \mathrm{~mL} / \mathrm{min} / 1.73 \mathrm{~m}^{2}$. Depending on the value of GFR and albuminuria, CKD is divided into five stages. Its importance is given by the fact that all CKD stages are associated with the increase of the risk of cardiovascular morbidity, the decrease of the quality of life and premature deaths, representing the ninth cause of death in the USA $^{8}$. Most often, between CKD and cardiovascular pathology (especially the presence of hypertension) there is a close relationship, so CKD contributes as an accelerator of CVD and the CVD deteriorates faster the GFR, accelerating CKD progression to stage 5, the final stage of CKD. The most common causes of CKD remain high blood pressure, diabetes, atherosclerosis and glomerulonephritis ${ }^{8}$. Patients with CKD stage $1-3$ are usually asymptomatic, clinical manifestations begin to appear with reduced GFR, especially in stages 4-5, when hydro-electrolytic disorders (most common hyperkalemia), endocrine disorders (including secondary anemia), metabolic acidosis, caloric protein malnutrition occur, all with a negative impact both on the general condition of the patient and the GFR. Because stage 3 seems to be the most common, it is extremely important to recognize the association with other pathologies (diabetes, CVD, especially hypertension, MS) and to treat them intensively, to try to slow down the reduction of GFR and secondary to delay the evolution of the patient towards stage 5 of GFR. This not only represents an immense financial burden, but also the quality of life of these patients is greatly affected, and the risk of mortality in patients undergoing renal replacement treatment is much higher?.

DM is considered nowadays a global health problem, recent data claiming that in 2017 there were over 450 million diabetic patients; also, it is estimated that in the future the incidence of this disease will rapidly increase $^{10}$, due to some relevant factors included in patient's life style: eating habits, level of physical activity, alcohol consumption, tobacco, and/or drugs, etc. The importance of this condition is based on the risk of premature death, representing itself an independent cardiovascular risk factor for CKD and many other complications (micro and macrovascular), that not only strongly influence the quality of life but also the morbidity and mortality (increasing by $2-4$ times the cardiovascular mortality) ${ }^{8,11}$.

Hyperuricemia is induced by alterations in purine metabolism and increased serum uric acid is associated with increased risk of developing T2DM, as shown by recent studies ${ }^{12}$. It is arbitrarily defined as serum uric acid values $>420 \mathrm{mmol} / \mathrm{L}$ in men and $>360 \mathrm{mmol} / \mathrm{L}$ in women, respectively $6-7 \mathrm{mg} / \mathrm{dL}$. The association of the two factors is frequent and the possible connections between the pathogenic mechanisms by which the presence of hyperuricemia influences and/or induces the appearance of T2DM have been studied. It seems that hyperuricemia is strongly associated with both CKD (which is negatively influenced by the proinflammatory role triggered at the endothelial level) and CVD, being a real connection between them, and the onset of T2DM negatively accentuates the risk of their individual progression, as well as the risk of mortality.

Uric acid itself is a paradox, being both a protective factor, with an antioxidant role, and a well-known pro-inflammatory/pro-oxidant role ${ }^{13}$. The antioxidant action seems to depend a lot on the presence of the hydrophobic environment, when the oxidative stress decreases. It is known that reactive oxygen species (ROS) are associated with local inflammation, nitric oxide $(\mathrm{NO})$ production, insulin resistance, activation of the renin-angiotensin system and fat accumulation, causing changes in adipocytes so that the pro-oxidant role is better studied and strongly associated with cardiovascular, diabetes and renal pathology $y^{14}$.

\section{THE OBJECTIVE OF THE STUDY}

Considering the strong and frequent association between MS, CKD, T2DM, associated or not with hyperuricemia, our study explored the impact 
of hyperuricemia on the prevalence of MS, as well as on the glomerular function in a group of T2DM patients.

\section{Materials AND Methods}

In this retrospective study there were included 300 patients with T2DM, hospitalized for one day in the diabetes clinic of the County Clinical Emergency Hospital, Oradea, Romania, between 01.01.2016-31.12.2018. The selection of patients was possible using a systematic sampling method, every tenth hospitalized patient being included in the research; all the data used for the analysis were obtained from the medical records. For each patient there were determined the following variables:

- anthropometric parameters (height, weight, body mass index (BMI));

- type and duration (in years) of T2DM;

- presence of CVD comorbidities (hypertension, myocardial infarction, ischemic heart disease), dyslipidemia, hepatic steatosis, presence of micro/ macrovascular complications (diabetic retinopathy, diabetic polyneuropathy, arteriopathy);

- biological tests values: blood glucose, current and previous glycosylated hemoglobin, liver tests, hemoglobin, current and previous creatinine, current and former GFR, uric acid, lipid profile (cholesterol, TGL, HDL, LDL-cholesterol, TGL/ HDL-ratio), the presence of proteinuria and/or changes in the urinary sediment;

- treatment for MS components (T2DM, hypertension, dyslipidemia), treatment of hyperuricemia and/or other treatments (antiplatelet/anticoagulant, neurotropic).

The inclusion criteria were as follows: age $>18$ years, confirmed T2DM and complete data in the medical records. The exclusion criteria were considered: incomplete data needed for the study, subjects under medication that may have influenced the results (glucocorticoids) and/or with major acute infections (not to influence blood glucose levels).

The study was carried out with the agreement of the Hospital Ethics Committee, no. 11379/07.05.2019 and it was conducted respecting the World Medical Association Code of Ethics - 1967, Declaration of Helsinki. Every patient signed an informed consent before being included in the study.

MS has been defined according to International Diabetes Federation ${ }^{15}$ as the presence of three of the following conditions: high blood pressure (systolic blood pressure (SBP) $\geq 130 \mathrm{mmHg}$ or diastolic blood pressure (DBP) $\geq 85 \mathrm{mmHg}$ or treatment for hypertension), hypertriglyceridemia $\geq 150 \mathrm{mg} / \mathrm{dL}$ or lipid-lowering treatment, increased fasting blood glucose
$>100 \mathrm{mg} / \mathrm{dL}$ or antidiabetic treatment, reduction of HDL-cholesterol $<40 \mathrm{mg} / \mathrm{dL}$ in men and $<50 \mathrm{mg} / \mathrm{dL}$ in women, for those with BMI $>30 \mathrm{~kg} / \mathrm{m}^{2}$ - central obesity can be affirmed, even if abdominal circumference was not measured.

Blood pressure values (according to the European Society of Cardiology/European Society of Hypertension 2018 Guidelines for the management of hypertension ${ }^{15}$ ) were defined as: normal $\mathrm{SBP}<130$ mm Hg, DBP<85 mm Hg; normal-high SBP between 130-139 mm Hg, DBP between 85-89 mmHg; target values for those with hypertension and treatment: below 140/90 mm Hg.

Serum uric acid was considered elevated if it had values above $6 \mathrm{mg} / \mathrm{dL}$ in women, respectively $7 \mathrm{mg} / \mathrm{dL}$ in $\mathrm{men}^{16,17}$. In the analysis performed there were included patients with hyperuricemia who have values above these thresholds and those who have normal serum uric acid values but have hyperuricemia treatment (regardless of the type of medication).

$\mathrm{CKD}$ was defined according to the guidelines by (1) reduction of GFR below $60 \mathrm{~mL} / \mathrm{min} / 1.73 \mathrm{~m}^{2}$, with a minimum duration of 3 months or (2) renal impairment lasting more than 3 months. Renal impairment can be diagnosed in the absence of knowledge of the etiology and consists of structural or functional abnormalities of the kidney reflected by: anomalies of urine examinations (proteinuria, albuminuria, hematuria, and leukocytosis), abnormalities of blood tests (nitrogen retention, dyselectrolitemias, metabolic acidosis), abnormalities of renal imaging investigations, pathological lesions of the kidneys at renal biopsy ${ }^{18}$.

Statistical analysis was performed using Biostat software version 5.9.8.5; to compare frequencies, Chi-squared test was used, and to find mean values the ANOVA test was used; $p$ values $<0.05$ were considered statistically significant.

\section{Results}

Following the analysis of the studied group, out of the 300 cases, 138 were identified with hyperuricemia and 162 with normo-uricemia. The prevalence of hyperuricemia was $46 \%$. The average age of the patients was 62 years. The characteristics of the patients with hyperuricemia and normo-uricemia are shown in Table 1. Among patients with hyperuricemia, the prevalence of obesity, hypertension, ischemic heart disease, CKD, MS and its components are statistically significantly higher than in patients with normo-uricemia; all these parameters are presented comparatively in Figures 1 and 2, and Table 2.

In patients with hyperuricemia, the mean values of SBP and DBP were statistically insignificant higher than in patients with normo-uricemia. Triglycerides 
Table 1. Comorbidities of patients with hyperuricemia/ normo-uricemia.

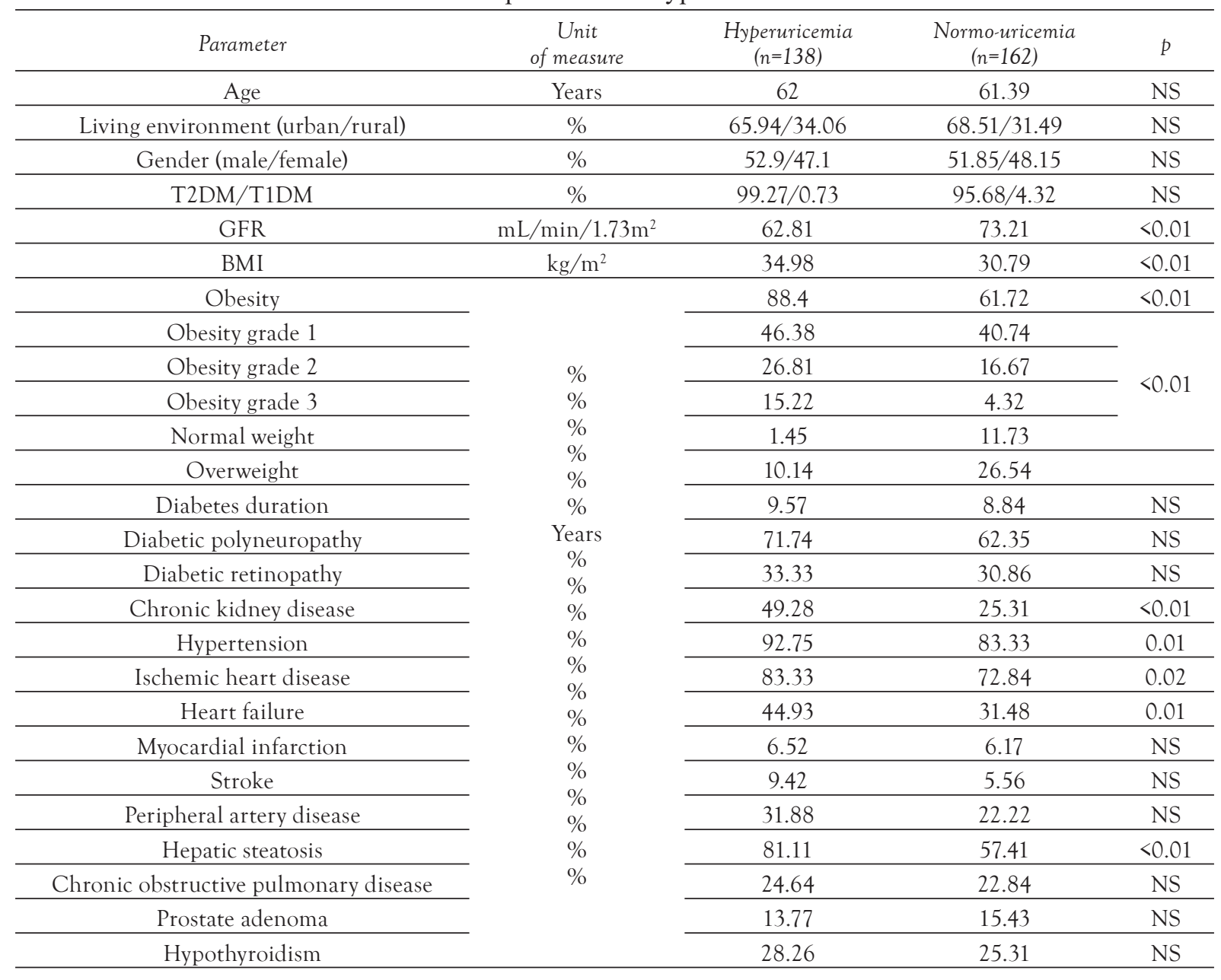

Table 2. Clinical/ paraclinical characteristics of patients with hyperuricemia/ normo-uricemia.

\begin{tabular}{ccccccc}
\hline Parameter & Unit of measure & $\begin{array}{c}\text { Hyperuricemia } \\
(n=138)\end{array}$ & Standard dev. & $\begin{array}{c}\text { Normo-uricemia } \\
(n=162)\end{array}$ & $\begin{array}{c}\text { Standard } \\
\text { dev. }\end{array}$ & $p$ \\
\hline SBP & $\mathrm{mm} \mathrm{Hg}$ & 145.13 & 18.57 & 143.56 & 19.7 & 0.48 \\
\hline DBP & $\mathrm{mm} \mathrm{Hg}$ & 86.11 & 11.94 & 85.37 & 12.33 & 0.6 \\
\hline Heart rate & beats/min & 80.08 & 12.31 & 78.88 & 11.48 & 0.38 \\
\hline $\begin{array}{c}\text { Ankle-brachial } \\
\text { index right foot }\end{array}$ & & 0.99 & 0.14 & 1.02 & 0.16 & 0.14 \\
\hline $\begin{array}{c}\text { Ankle-brachial } \\
\text { index left foot }\end{array}$ & & 0.99 & 0.14 & 1.01 & 0.15 & 0.18 \\
\hline Glycaemia & $\mathrm{mg} / \mathrm{dL}$ & 175.94 & 65.57 & 181.8 & 81.49 & 0.49 \\
\hline Cholesterol & & 191.48 & 53.21 & 189.01 & 55.18 & 0.69 \\
\hline Triglycerides & & 227.34 & $(117.5,272.5)$ & 174.96 & $(94,171.25)$ & $<0.01$ \\
\hline LDL-cholesterol & & 110.97 & 47.08 & 117.82 & 48.9 & 0.23 \\
\hline HDL-cholesterol & & 8.58 & 46.98 & 13.59 & $<0.01$ \\
\hline TRIG/HDL-ratio & & 8.34 & 4.02 & 4.46 & 15.39 & 0.04 \\
\hline CRP & $\mathrm{mg} / \mathrm{dL}$ & 2.41 & 4.53 & 0.72 & 0.89 & $<0.01$ \\
\hline VSH & $\mathrm{mm} / \mathrm{h}$ & 21.82 & 17.43 & 16.63 & 13.35 & $<0.01$ \\
\hline HbAlc & $\%$ & 8.04 & 1.74 & 8.07 & 2.01 & 0.75 \\
\hline Creatinine & $\mathrm{mg} / \mathrm{dL}$ & 1.28 & 0.73 & 1.04 & 0.38 & $<0.01$ \\
\hline GFR & $\mathrm{mL} / \mathrm{min} / 1.73 \mathrm{~m}^{2}$ & 62.96 & 24.58 & 73.1 & 22.09 & $<0.01$ \\
\hline Urea & $\mathrm{mg} / \mathrm{dL}$ & 49.2 & 25.65 & 41.67 & 18.28 & $<0.01$ \\
\hline
\end{tabular}




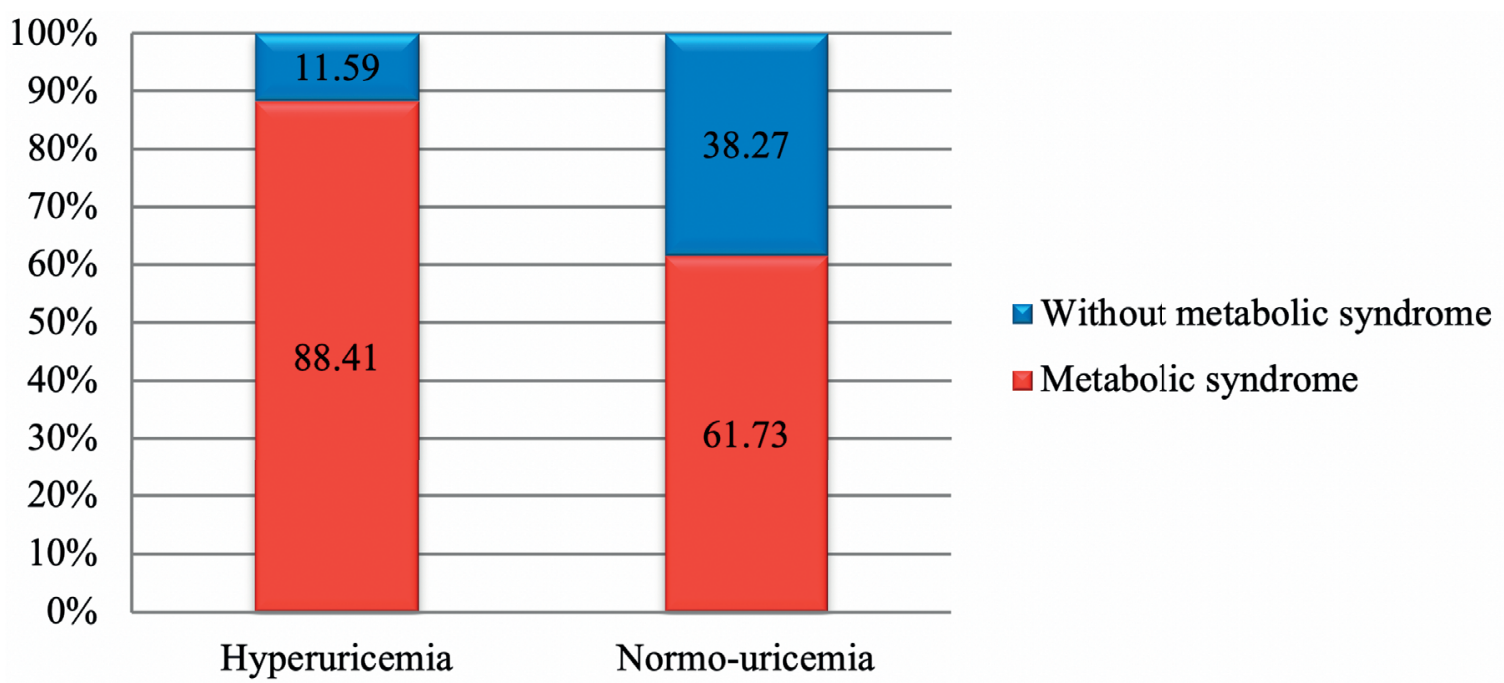

Figure 1. Prevalence of MS in patients with hyperuricemia/ normo-uricemia.

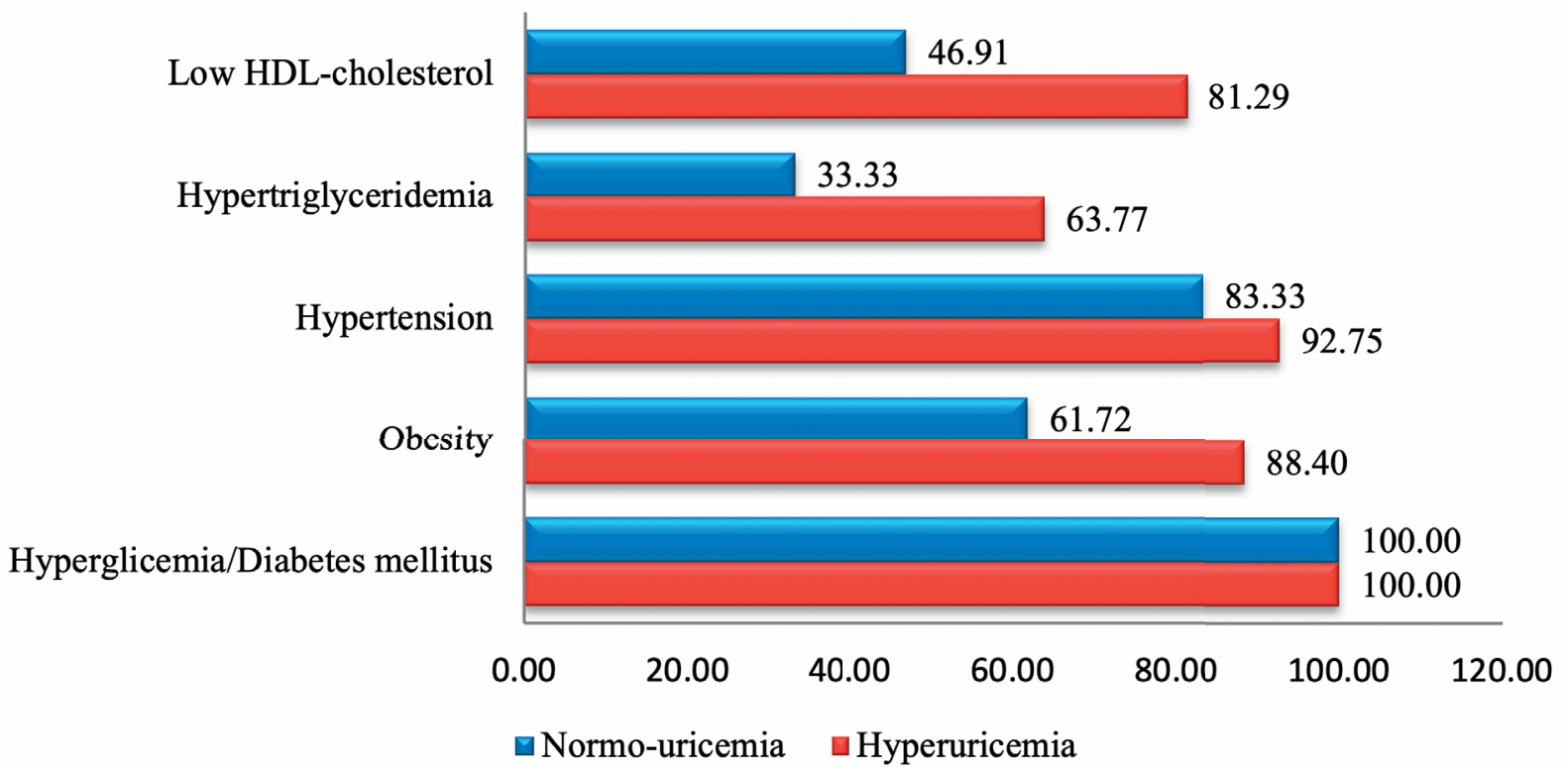

Figure 2. Prevalence of components of MS in T2DM patients with hyperuricemia/ normo-uricemia.

had statistically significant higher values in the hyperuricemia group $(\mathrm{p}<0.01)$, the mean HDL-cholesterol value being statistically significant lower in the hyperuricemia group ( $\mathrm{p}<0.01)$. The TRIG/HDL-cholesterol ratio is statistically significant higher in patients with hyperuricemia compared to those without hyperuricemia $(p=0.04)$. C-reactive protein and erythrocyte sedimentation rate values were statistically significant higher in patients with hyperuricemia $(p<0.01)$. The current renal function evidenced by creatinine, blood urea nitrogen and GFR, was statistically significant lower in patients with hyperuricemia $(\mathrm{p}<0.01)$ (Table 2).

Regarding the analysis of groups from the point of view of the renal function, quantified by GFR, there are statistically significant differences between groups, the prevalence of the altered renal function being statistically significant higher in the hyperuricemia patients (Table 3). The association between hyperuricemia and MS is characterized by the high prevalence of $\mathrm{CKD}$, which demonstrates the negative impact that the two parameters have on the renal function (Figure 3).

\section{Discussion}

Hyperuricemia is known as a risk factor for $\mathrm{T} 2 \mathrm{DM}$, as it causes proinflammatory endocrine imbalance in vascular smooth muscle cells and adipose 


\section{$\square$ Normal GFR $\quad \square \mathrm{CKD}$}

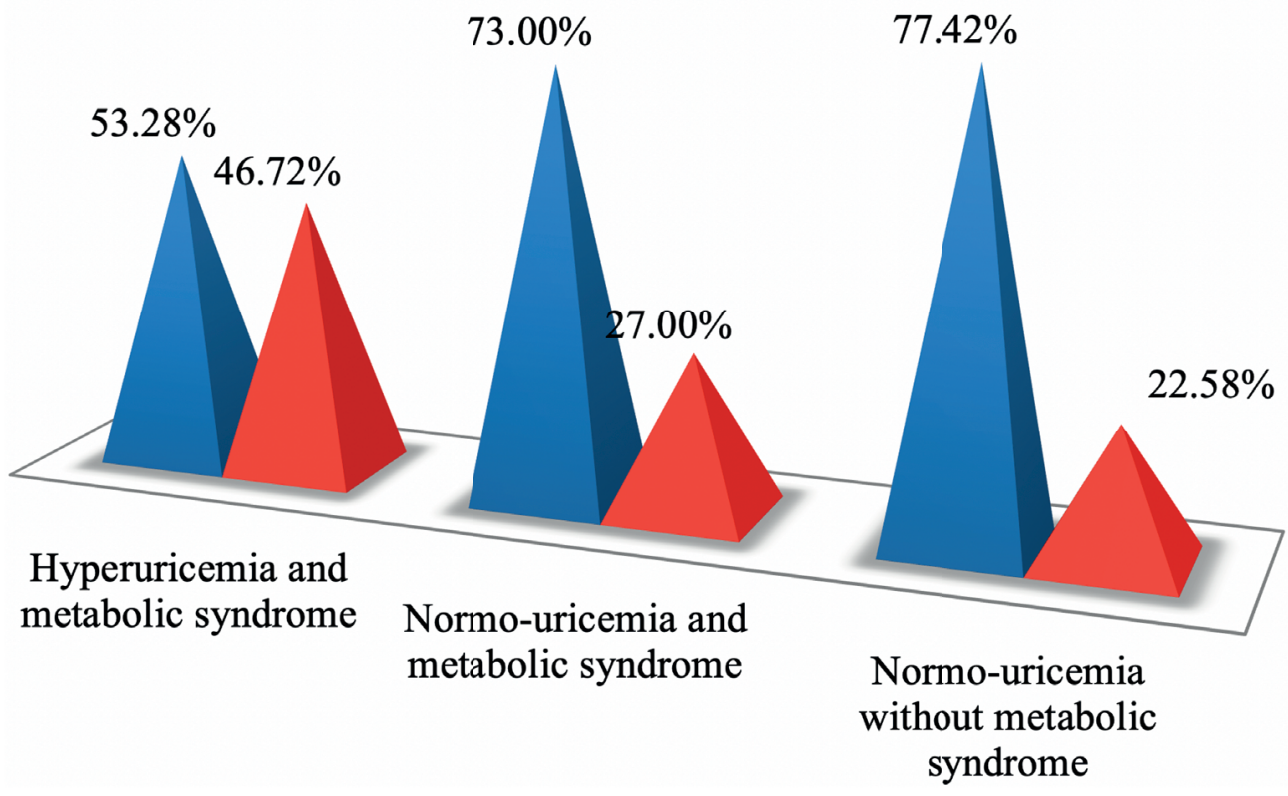

Figure 3. The association between uric acid, MS and CKD.

tissue, which results in morphological changes in cell surface, as well as changes in insulin resistance ${ }^{19,20}$. Through the mechanisms identified (which lead to an increased risk of T2DM in patients suffering from this imbalance), hyperuricemia produces: increased inflammation (elevated levels of IL-1, IL-6 and TNF-a), increased level/ concentrations of ROS (uric acid has antioxidant actions in plasma and prooxidant action in tissues), endothelial dysfunction, by reducing the bioavailability of $\mathrm{NO}$ and inhibiting the insulin pathway ${ }^{21}$.

This study shows that the prevalence of hyperuricemia in a population of 300 patients with T2DM was $46 \%$. This prevalence is much higher than the prevalence of hyperuricemia reported in studies performed on general population; a study performed on the US population demonstrated a prevalence of $21.4 \%{ }^{21}$. Data from the literature demonstrated that hyperuricemia in patients with T2DM is associated with an increased risk of macrovascular and microvascular complications. There is a J-shape curve between serum uric acid values and macrovascular complications in patients with $\mathrm{T}_{2} \mathrm{DM}^{22}$; it is also highlighted in the current study, where the patients with hyperuricemia had a statistically significant higher prevalence of ischemic heart disease, hypertension ${ }^{23}$ and heart failure. Uric acid is also associated with microvascular complications, among them being the diabetic nephropathy. At the kidney level, hyperuricemia
Table 3. Prevalence of glomerular filtration rate intervals among patients with hyperuricemia/ normo-uricemia $(\mathrm{p}<0.01)$

\begin{tabular}{ccccc}
\hline GFR & \multicolumn{2}{c}{$\begin{array}{c}\text { Hyperuricemia } \\
(n=138)\end{array}$} & \multicolumn{2}{c}{$\begin{array}{c}\text { Normo-uricemia } \\
(n=162)\end{array}$} \\
\hline $\mathrm{mL} / \mathrm{min}$ & No. & $\%$ & No. & $\%$ \\
\hline Normal & 18 & 13.04 & 38 & 23.46 \\
\hline $60-90$ & 52 & 37.68 & 83 & 51.23 \\
\hline $30-59$ & 55 & 39.86 & 36 & 22.22 \\
\hline $15-29$ & 12 & 8.70 & 5 & 3.09 \\
\hline GFR $<15$ & 1 & 0.72 & 0 & 0.00 \\
\hline
\end{tabular}

increases oxidative stress and activates the renin-angiotensin-aldosterone system ${ }^{21}$. Studies demonstrate that serum uric acid is an independent risk factor for reduced glomerular function in patients with T2DM. It was found that even high-normal values of uric acid in patients with T2DM represent a risk factor for progression to CKD stage 3 or higher, in the follow-up period, compared with patients who had lower values of serum uric acid ${ }^{24}$.

Hyperuricemia was associated with all the other components of MS: hypertension, obesity, dyslipidemia $^{24}$. Data from the literature show that the presence of serum uric acid $\geq 7 \mathrm{mg} / \mathrm{dL}$ was associated with $80 \%$ higher risk of developing hypertension $^{25}$. Hyperuricemia was associated with 
atherosclerotic disease, the pathogenic mechanisms being endothelial dysfunction generated by uric acid crystals, increased ROS generation, oxidation of LDL-cholesterol particles, increased proliferation of vascular smooth muscle cells ${ }^{26}$. In patients with hyperuricemia, an elevated level of serum triglycerides is found due to insulin resistance and free fatty acids that accumulate in the liver, leading to hepatic steatosis $^{27}$. Hyperuricemia is associated with obesity, increasing monocyte infiltration in the adipose tissue and decreasing the lipid turnover ${ }^{28}$. In this research, hyperuricemia in patients with T2DM was associated with a statistically significant higher prevalence of all the components of MS. Recent studies suggest that increased serum uric acid is associated not only with increased cardiovascular morbidity risk but also with increased cancer risk, especially breast cancer, because it promotes inflammation and more aggressive tumor cell biology ${ }^{29}$.

It is advisable for dietitians and those who benefit from public health education to pay more attention to the target values of biological parameters, especially regarding their MS-related illnesses. Associated medical education should be provided when needed. For patients with only hyperuricemia, dietary health education related to MS should be offered as additional help for patients, in order to better control their uric acid value.

\section{Conclusions}

Hyperuricemia is associated with increased MS prevalence and increased prevalence of CKD in T2DM patients. Identifying hyperuricemia in these patients is useful for carefully identifying cardiovascular risk factors and silent CVD in T2DM patients and treating hyperuricemia itself appears to be useful in reducing cardiovascular risk. Obviously, more attention should be paid to the diseases induced or potentiated by hyperuricemia. The incidence of this parameter/pathology can be decreased by changing the eating habits (less foods containing high levels of purine - organs of animal origin, seafood etc, while increasing the consumption of fruits, vegetables, eggs and milk). Health education, promoted in order to reduce the incidence of some pathologies, must be made in such a way as to lead to the awareness of the population regarding the dangers of the appearance/ existence of hyperuricemia, but also of its complications.

\section{Author Contributions:}

Conceptualization, A.B. and S.B.; methodology, A.B.; software, C.M.V.; validation, T.B. and L.L.; formal analysis, T.B. and F.U.; investigation, A.B.; resources, R.A.C.A.; data curation, A.B. and C.M.V.; writing-original draft preparation, A.B.; writing-review and editing, S.B, I.R.,C.M.V.; visualization, F.U. and R.A.C.A.; supervision, S.B.; project administration, L.L. All the authors have read and agreed with the final version of the article.

\section{Compliance with Ethics Requirements:}

„The authors declare no conflict of interest regarding this article"

„The authors declare that all the procedures and experiments of this study respect the ethical standards in the Helsinki Declaration of 1975, as revised in 2008(5), as well as the national law. Informed consent was obtained from all the patients included in the study"

"No funding for this study"

\section{Acknowledgements:}

None

\section{References}

1. Alberti KG, Eckel RH, Grundy SM, et al. Harmonizing the metabolic syndrome: a joint interim statement of the International Diabetes Federation Task Force on Epidemiology and Prevention; National Heart, Lung, and Blood Institute; American Heart Association; World Heart Federation; International Atherosclerosis Society; and International Association for the Study of Obesity. Circulation. 2009;120:1640-1655.

2. Wang J, Ruotsalainen S, Moilanen L, Lepisto P, Laakso M, Kuusisto J. The metabolic syndrome predicts cardiovascular mortality: a 13-year follow-up study in elderly non-diabetic Finns. European Heart Journal. 2007;28: 857-864.

3. Ford ES. The metabolic syndrome and mortality from cardiovascular disease and all-causes: findings from the National Health and Nutrition Examination Survey II Mortality Study. Atherosclerosis. 2004;173: 309-314.

4. Keane D, Kelly S, Healy NP. Diet and metabolic syndrome: an overview. Current Vascular Pharmacology. 2013;11: 842-857.

5. Mahalingaiah S, Diamanti-Kandarakis E. Targets to treat metabolic syndrome in polycystic ovary syndrome. Expert Opinion on Therapeutic Targets. 2015;19:1561-1574.

6. Beltran-Sanchez H, Harhay MO, Harhay MM, et al. Prevalence and trends of metabolic syndrome in the adult U.S. population, 1999-2010. Journal of the American College of Cardiology .2013;62: 697-703.

7. Hill NR, Fatoba ST, Oke JL, et al. Global prevalence of chronic kidney disease - a systematic review and meta-analysis. PLoS One. 2016;11: e0158765.

8. Moisi MI, Rus M, Bungau S, et al. Acute coronary syndromes in chronic kidney disease: clinical and therapeutic characteristics. Medicina (Kaunas). 2020;56(3): pii: E118.

9. Gansevoort RT, Correa-Rotter R, Hemmelgarn BR, et al. Chronic kidney disease and cardiovascular risk: epidemiology, mechanisms, and prevention. Lancet. 2013;382: 339-352.

10. National Institute of Diabetes and Digestive and Kidney Diseases, US Renal Data System, USRDS 2011 Annual Data Report: Atlas of Chronic Kidney Disease and End-Stage 
Renal Disease in the United States. Available at: https:// www.usrds.org/atlas11.aspx (accessed on: 05.04.2020)

11. Pugh D, Gallacher PJ, Dhaun N. Management of hypertension in chronic kidney disease. Drugs. 2019;79: 365-379.

12. Wong CKH, Chen J, Fung SKS, et al. Direct and indirect costs of end-stage renal disease patients in the first and second years after initiation of nocturnal home hemodialysis, hospital hemodialysis and peritoneal dialysis. Nephrology Dialysis Transplant. 2019;34: 1565-1576.

13. Liu J, Zhao Z, Mu Y, et al. Gender differences in the association between serum uric acid and prediabetes: a six-year longitudinal cohort study. International Journal of Environmental Research and Public Health. 2018;15: 1560.

14. Sautin YY, Johnson RJ. Uric acid: the oxidant-antioxidant paradox. Nucleosides Nucleotides Nucleic Acids. 2008;27: 608-619.

15. Kang DH, Ha SK. Uric acid puzzle: dual role as anti-oxidant and pro-oxidant. Electrolyte and Blood Pressure. 2014;12: 1-6.

16. William B, Mancia G, Spiering W, et al. Grupul de lucru pentru managementul hipertensiunii arteriale al Societatii Europene de Cardiologie (ESC) si al Societatii Europene de Hipertensiune (ESH), Ghidul ESC/ESH 2018 pentru managementul hipertensiunii arteriale (in English: Working Group for the Management of Hypertension of the European Society of Cardiology (ESC) and of the European Society of Hypertension (ESH), ESC/ESH Guide 2018 for the management of hypertension). Romanian Journal of Cardiology. 2018;28(4): 69-177.

17. Li Q, Li X, Wang J, et al. Diagnosis and treatment for hyperuricemia and gout: a systematic review of clinical practice guidelines and consensus statements. BMJ Open. 2019;9: e026677.

18. Shroff GR, Frederick PD, Herzog CA. Renal failure and acute myocardial infarction: Clinical characteristics in patients with advanced chronic kidney disease, on dialysis, and without chronic kidney disease. A collaborative project of the United States Renal Data System/National Institutes of Health and the National Registry of Myocardial Infarction. American Heart Journal. 2012;163:399c406.

19. Baldwin WMS, Marek G, Wymer D. et al. Hyperuricemia as a mediator of the proinflammatory endocrine imbalance in the adipose tissue in a murine model of the metabolic syndrome. Diabetes. 2011;60(4): 1258 -1269.

20. Zhu Y, Pandya BJ, Choi HK. Prevalence of gout and hyperuricemia in the US general population: the National Health and Nutrition Examination Survey 2007-2008. Arthritis $\mathcal{E}$ Rheumatology. 2011;63: 3136-3141.

21. Qing X, Jie L, Yancheng X. Insulin resistance, obesity, and metabolic syndrome: common inflammatory pathways leading to type 2 diabetes. International Jornal of Endocrinology. 2019;2019: Article ID 9691345.

22. Yan DD, Wang J, Jiang F et al. A causal relationship between uric acid and diabetic macrovascular disease in Chinese type 2 diabetes patients: a Mendelian randomization analysis. International Journal of Cardiology. 2016;214:194-199.

23. Stoicescu M, Csepento C, Mutiu G, Bungau S. The role of increased plasmatic renin level in the pathogenesis of arterial hypertension in young adults. Romanian Journal of Morphology and Embriology. 2011;52(1 Suppl.): 419-423.

24. KIM WJ, KIM SS, BAE MJ, et al. High-normal serum uric acid predicts the development of chronic kidney disease in patients with type 2 diabetes mellitus and preserved kidney function. Jornal of Diabetes Complications. 2014;28: 130-134.

25. Wang H, Zhang H, Sun L, Guo W. Roles of hyperuricemia in metabolic syndrome and cardiac-kidney-vascular system diseases. American Journal of Translational Research. 2018;10(9): 2749-2763.

26. Yang Y, Tian J, Zeng C, et al. Relationship between hyperuricemia and risk of coronary heart disease in a middle-aged and elderly Chinese population. Journal of International Medical Research. 2017;45: 254-260.

27. Kuwabara M, Borghi C, Cicero AF, et al. Elevated serum uric acid increases risks for developing high LDL cholesterol and hypertriglyceridemia: a five-year cohort study in Japan. International Journal of Cardiology. 2018;261: 183-188.

28. Liu J, Xu C, Ying L, et al. Relationship of serum uric acid level with non-alcoholic fatty liver disease and its inflammation progression in non-obese adults. Hepatology Research. 2017;47: E104cE112

29. Vona-Davis L, Howard-Mcnatt M, Rose DP. Adiposity, type 2 diabetes and the metabolic syndrome in breast cancer. Obesity Reviews. 2007;8: 395-408. 